p-ISSN: $2338-4387$

e-ISSN: $2580-3247$

\title{
INVENTARISASI TUMBUHAN PAKU (PTERIDOPHYTA) DI KAWASAN KAMPUS IAIN PALANGKA RAYA SEBAGAI ALTERNATIF MEDIA PEMBELAJARAN MATERI KLASIFIKASI TUMBUHAN
}

\author{
Ayatusa'adah dan Nor Apriyani Dewi \\ IAIN Palangka Raya \\ e-mail: ayatussadah@iain-palangkaraya.ac.id
}

\begin{abstract}
Abstrak
Tujuan Penelitian ini adalah menginventarisasi tumbuhan paku di kawasan kampus IAIN Palangka Raya sebagai alternatif media pembelajaran materi klasifikasi tumbuhan untuk siswa kelas X SMA. Metode yang digunakan adalah penelitian kualitatif melalui kegiatan survei untuk menginventarisasi tumbuhan paku. Pengumpulan data dilakukan dengan teknik mengikuti jalur jalan (track) yang dilakukan dengan mengumpulkan sebanyak mungkin jenis yang dijumpai dan tumbuh di kawasan kampus IAIN Palangka Raya. Identifikasi jenis tumbuhan paku menggunakan kunci determinasi. Data hasil penelitian dianalisis secara deskriptif untuk dihubungkan dengan pengembangan alternatif media pembelajaran. Hasil inventarisasi diperoleh sebelas spesies pteridophyta dari famili Blechnaceae satu spesies, Pteridaceae dua spesies, Polypodiaceae satu spesies, Dryopteridaceae empat spesies, Polipodiacea dua spesies dan Woodsiaceae satu spesies. Berdasarkan cara hidupnya sebelas paku yang ditemukan terdiri dari enam jenis Pteridophyta teresterial, dua jenis Pteridophyta epifit dan teresterial, dan tiga jenis Pteridophyta epifit. Hasil penelitian dapat digunakan sebagai alternatif media pembelajaran materi klasifikasi tumbuhan untuk siswa SMA kelas $\mathrm{X}$.
\end{abstract}

Kata kunci: Inventarisasi; Media Pembelajaran; Pteridophyta

\section{Abstract}

The purpose of this research is to have an inventory on Fern-plants in the area of IAIN Palangka Raya as an alternative media to discuss or learn about the classification of plants for high school students. The method applied was qualitative research through survey activities to have an inventory on fern-plants. In collecting the data, the procedure was done by tracking the ferns growing area and collecting every kind of ferns species found in IAIN Palangka Raya. Identification of ferns species were using the key of determination. The data of the research were analyzed descriptively to get connected with the development of alternative learning media. The inventory result has been obtained eleven species of pteridophyta, one species of Blechnaceae family, two species of Pteridaceae, one species of Polypodiaceae, four species of Dryopteridaceae, two species of Polipodiacea and ome species of Woodsiaceae. Based on the nature of the ferns, eleven ferns are found. They consist of six types of terrestrial Pteridophyta, two types of Pteridophyta epiphytes and teresters, and three types of Pteridophyta epiphytes. The results of the research can be used as an alternative media for teaching and learning the topic of plant classification for high school students.

Keywords: Inventory, Instructional Media, Pteridophyta

\section{PENDAHULUAN}

Tumbuhan paku (Pteridophyta) merupakan tumbuhan yang dapat hidup dengan mudah di berbagai macam habitat baik secara epifit, terestrial maupun di air. Menurut Suryana (2009) Penyebaran dan keanekaragaman tumbuhan paku memang sangat besar, 
begitu pula dengan potensi dan manfaatnya yang cukup penting baik untuk tanaman hias, sayuran, obat-obatan hingga peranannya sebagai keseimbangan ekosistem. Namun, data dasar tumbuhan paku berkenaan dengan komposisi, keanekaragaman dan distribusi belum banyak terungkap. Pteridophyta merupakan tumbuhan berpembuluh yang tidak berbiji, memiliki susunan tubuh khas yang membedakannya dengan tumbuhan yang lain. Pteridophyta disebut sebagai tracheophyta berspora, yaitu kelompok tumbuhan yang berpembuluh dan berkembang biak dengan spora (Nurcahyati, 2010). Pteridophyta memiliki jenis yang heterogen, baik ditinjau dari segi habitus maupun cara hidupnya (Tjitrosoepomo, 2005). Kinho (2009) menjelaskan bahwa pteridophyta merupakan suatu divisio tumbuhan yang telah memiliki sistem pembuluh sejati (kormus), artinya tubuhnya dengan nyata dapat dibedakan dalam tiga bagian pokok yaitu akar,batang dan daun. Namun demikian, Pteridophyta tidak menghasilkan biji untuk reproduksinya. Kelompok tumbuhan ini masih menggunakan spora sebagai alat perbanyakan generatifnya, sama seperti lumut dan fungi.

Pteridophyta tersebar luas dari tropika yang lembab hingga melampaui lingkaran Afrika. Sedangkan jumlah yang teramat besar dijumpai di hutan-hutan tropika dan tumbuh dengan subur (di daerah beriklim sedang, di hutan-hutan, padang rumput yang lembab, sepanjang sisi jalan dan sungai) (Tjitrosomo et al, 1983).Di permukaan bumi ini dilaporkan terdapat 13.000 jenis pteridophyta. Di kawasan Malaysia yang terdiri dari hampir kepulauan Indonesia, Filipina, Guinea dan Australia Utara diperkirakan terdapat 4.000 jenis paku yang mayoritasnya adalah Filicinae (Whitten, 1995 dalam Lubis, 2009). Menurut Loveless (1999) pteridophyta diwakili oleh kurang dari 10.000 jenis yang hidup, tetapi karena ukurannya yang besar dan karakteristiknya yang khas, pteridophyta merupakan komponen vegetasi yang menonjol. Total spesies yang diketahui hampir 10.000 (diperkirakan 3.000 di antaranya tumbuh di Indonesia).

Hasil penelitian Rizky et al (2016) di Kawasan Wisata Air Terjun Dholo, Kabupaten Kediri ditemukan 22 spesies tumbuhan paku dari 18 genus, 13 family tumbuhan paku. Dari 22 spesies terdapat 17 spesies tumbuhan paku terestrial dan 5 spesies tumbuhan paku epifit. Darma dan Pening (2007) menemukan tumbuhan paku didominasi oleh marga Cyclosorus, Asplenium, Athyrium, dan Pteris yang tumbuh menutupi dasar hutan di daerah-daerah lembab terutama di pinggir sungai yang berair bahwa Di kawasan hutan Taman Nasional Laiwangi- Wanggameti. Fitriani (2006), kawasan Hutan Baning Kabupaten Sintang menemukan 13 jenis tumbuhan paku dengan famili terbanyak Polypodiaceae. Ekoyani (2007), kawasan Hutan Lindung Gunung Bawang Kabupaten Bengkayang menemukan 20 jenis tumbuhan paku dengan famili terbanyak Dennstaedtiaceae. 
Peraturan Menteri Pendidikan dan Kebudayaan Nomor 22 Tahun 2016 proses pembelajaran pada satuan pendidikan diselanggarakan secara interaktif, inspiratif, menyenagkan, menantang, memotivasi peserta didik untuk berpartisipasi aktif serta memberikan ruang yang cukup bagi prakarsa, kreativitas dan kemandirian sesuai dengan bakat, minat dan perkembangan fisik serta psikologis peserta didik. Menurut Novitasari (2010), dominasi guru dalam pembelajaran akan meminimalkan peran siswa sebagai pembelajar, berkurangnya keaktifan, siswa menjadi bosan, tidak maumemperhatikan penjelasan guru, bahkan kurang termotivasi untuk mengikuti pelajaran sehingga siswa yang seharusnya menjadi aktor utama tidak mampu mengoptimalkan proses belajarnya. Oleh sebab itu diperlukan pembelajaran yang interaktit dan inspiratif sehingga peserta didik berpartisipasi aktif dalam pembelajaran. Salah satu cara untuk menciptakan pembelajaran yang interktif dan inspiratif adalah dengan menggunakan media pemnelajaran.

Media pembelajaran adalah segala alat fisik yang digunakan untuk menyampaikan isi materi pengajaran (Taufik et al, 2014). Salah satu manfaat media pembelajaran menurut Susilana dan Riyana (2009) dapat membuat konkrit konsep-konsep yang abstrak. Pengklasifikasian tumbuhan yang dirasa abstrak akan menjadi lebih kongkrit jika dalam pembelajarannya menggunakan media pembelajaran. Melalui penggunaan media pembelajaran, penanaman konsep, prinsip, dan hukum IPA akan menghasilkan pembelajaran yang efektif (Widiyatmoko, et al, 2012).

\section{METODE}

Penelitian ini merupakan penelitian kualitatif, melalui kegiatan survey untuk menginventarisasi tumbuhan paku di kawasan kampus IAIN Palangka Raya serta untuk mendapatkan alternatif media pembelajaran pada materi klasifikasi tumbuhan untuk siswa SMA kelas $\mathrm{X}$. Pengumpulan data dilakukan dengan teknik mengikuti jalur jalan (track) yang dilakukan dengan mengumpulkan sebanyak mungkin jenis yang dijumpai dan tumbuh di kawasan kampus IAIN Palangka Raya. Identifikasi jenis tumbuhan paku menggunakan kunci determinasi pada buku flora Steenis, et al (2008). Data hasil penelitian dianalisis secara deskriptif untuk dihubungkan dengan pengembangan alternatif media pembelajaran. Data yang dicatat terdiri atas nama jenis, ciri dan ukuran morfologi tumbuhan, lokasi tempat tumbuh, dan letak sorus, serta potensi pemanfaatan. Observasi pengambilan objek dilakukan di kawasan Kampus IAIN Palangka Raya Kalimantan Tengah pada Desember 2016. 


\section{HASIL DAN PEMBAHASAN}

Hasil penelitian yang dilakukan di Kawasan Kampus IAIN Palangka Raya ditemukan 11 Pteridophyta yang terdiri dari famili Blechnaceae, Pteridaceae, Polypodiaceae, Dryopteridaceae, dan Woodsiaceae. Pteridophyta yang ditemukan yaitu Stenochlaena palustris, Pteris vittata, Peteris longifolia, Pityrogramma calomelanos, Nephrolepis hirsutula, Nephrolepis falcata, Nephrolepis cordifolia, Dryopterisfilix-mas, Adiantum tenerum, Adiantum peruvianum, Athrium Sp.

Stenochlaena palustris (Kalakai) adalah paku-pakuan teresterial ketika masih muda, setelah dewasaakan menjalar atau hidup epifit pada tumbuhan yang berada disekitarnya. Stenochlaena palustris ditemukan disamping lapangan futsal, selain disamping lapangan futsal Stenochlaena palustris juga ditemukan diberbagai tempat seperti di belakang gedung Aula, Rektorat dan Ruang Dosen. Pengamatan di lapangan menunjukkan tumbuhan ini hidup di habitat rawa gambut, memiliki sistemperakaran serabut, tinggi batang mencapai $60 \mathrm{~cm}$, berwarna hijau. Daun merupakan daun majemuk menyirip genap dengan jumlah anak daun yang genap menurut Gembong (2009). Kedudukan anak daun berhadap-hadapan, berwarna hijau dengan tektur lembut ketika masih muda danberwarna merah kecoklatan bertangkai pendek, sedangkan pada daun yang dewasa berwana hijau, permukaan daunnya kasar. Panjang daun dewasa $11 \mathrm{~cm}$, lebar 2,7 cm, ujung daun meruncing, tepi daun bergerigi kasar/halus.Sedangkan pada daun yang muda bertepi rata. Pada Daun muda berwarna merah kecoklatan bertangkai pendek,berbentuk lanset, dengan lebar $2 \mathrm{~cm}$ berwarna hijau dan panjang $6 \mathrm{~cm}$.Sorus pada Stenochlaena palustristidak ditemukan karena pada tumbuhan yang diamati masih muda. Stenochlaena palustris berpotensi sebagai bahan pangan/sayuran pada daun yang masih muda yang berwarna merah kecoklatan.

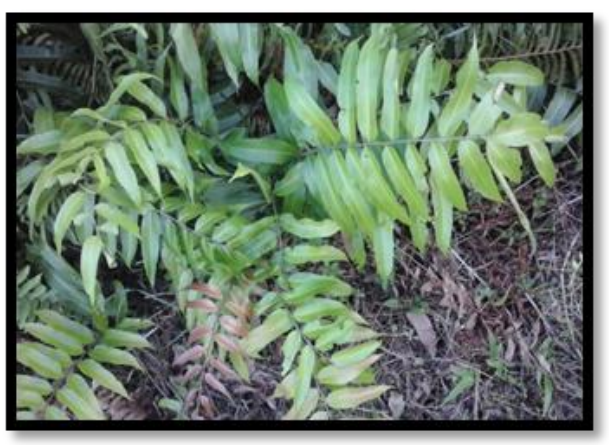

Gambar 1. Stenochlaena palustris

Pteris vittata (paku tanah) adalah paku epifit, pengamatan dilapangan menunjukkan tumbuhan ini hidup di menempel pada batu-batuan yang ditemukan dibelakang Aula menempel pada bebatuan yang berada di selokan. Pteris vittatamemiliki akar serabut, tinggi batang, mencapai $20 \mathrm{~cm}$, bentuk batang bulat, beruas-ruas panjang, permukaan 
batang halus, warna batang hijau kecoklatan.Jenis daun Pteris vittata adalah majemukmenyirip genap dengan jumlah anak daun yang genap, bentuk daunya memanjang, berukuran $\pm 3,5 \mathrm{~cm}$, lebar daun $0,7 \mathrm{~cm}$, ujung daun merucing, tepi daun rata, daun berwarna hijau dengan permukaan daun yang kasar. Sorus pada Pteris vittata terletak dipermukaan bawah daun berwarna coklat.

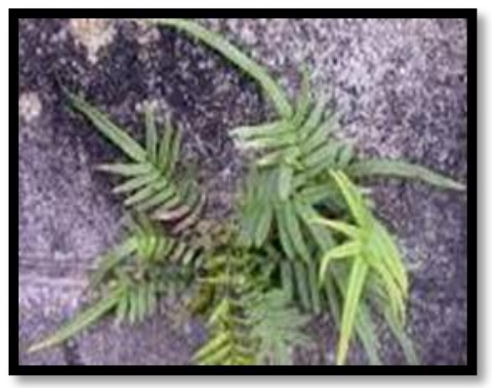

Gambar 2.Pterisvittata

Pteris longifolia (paku tanah) adalah jenis paku teresterial, ditemukan di samping lapangan futsal. Tumbuhan ini hidup di rawa gambut, memiliki sistem perakaran serabut berwarna coklat. Tinggi batang mencapai $\pm 90 \mathrm{~cm}$, bentuknya bulat berwarna hitam mengkilat. Batang pada tumbuhan ini berwarna hijau muda.Daun merupakan daun majemuk menyirip genap dengan jumlah anak daun yang genap, daunberwarna hijau muda tersusun berselang seling, ujung daun runcing, tepinya bergerigi halus dengan tekstur yang lembut dan tipis. Panjang daun $2 \mathrm{~cm}$ dan lebar $0,7 \mathrm{~cm}$. Daun mudaujung daun bagian pucuk daun menggulung. Pada Pteris longifolia tidak titemukan adanya sorus karena daun yang diamati masih muda sehingga sorusnya tidak terlihat.. Pteris longifolia memiliki potensi sebagai tanaman hias kaena memiliki keindahan yang cukup menarik untuk dijadikan sebagai tanaman hias (Purnawati, et al 2015).

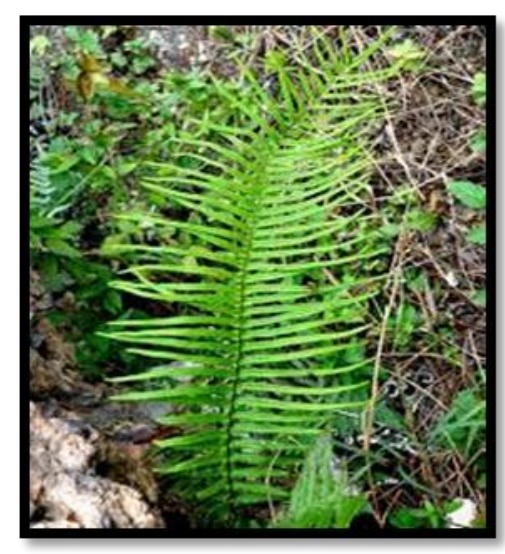

Gambar 3. Pteris longifolia

Pityrogramma calomelanos (paku perak) merupakan tumbuhan epifit, hidup menempel pada tumbuhan yang lain. Tumbuhan iniditemukan dibelakang Aula. Bentuk akar serabut berwarna hitam, batang berwarna coklat kehitaman, pada ujung batang berwarna coklat kehijauan.Tinggi batang berkisar $70 \mathrm{~m}$. Daun merupakan daun 
majemukmenyirip genap dengan jumlah anak daun yang genap,anak daun berselangseling,warna daun hijau muda. Panjang daun 4-5 cm, lebar daun 0,7 cm, ujung daun runcing, tepi daun bergerigi. Sorus Pityrogramma calomelanosketika diamati tidak terdapat adanya sorus karena daun yang diamati masih muda. Biasanya sorus terletak diujung daun dengan berbentuk memanjang berwarna coklat kehitaman. Dari segi keindahanPityrogramma calomelanosberpotensisebagai tanaman hias (Irawati, 2012).

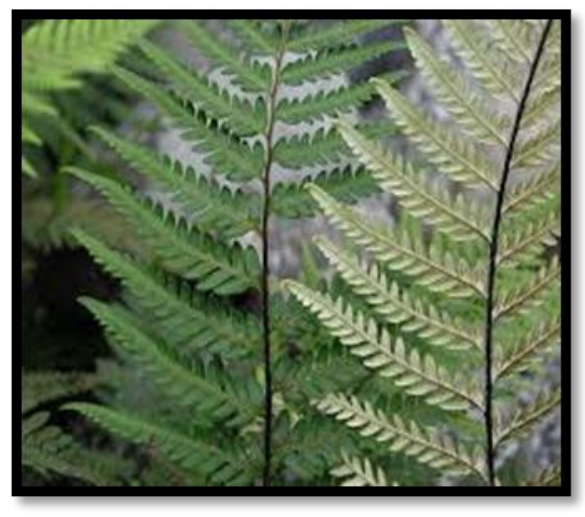

Gambar 4. Pityrogramma calomelanos

Nephrolepis hirsutula (paku kinca) adalah tumbuh ini teresterial memiliki akar serabutyang ditemukan di samping lapangan futsal. Habitat tumbuhan ini di rawa gambut.Tinggi batang $200 \mathrm{~cm}$, berwarna coklat. Pada batang terdapat bulu-bulu halus berwarna putih, akan tetapi pada ujung batang bagian pucuk daun berwarna hijau muda. Daun merupakan daun majemuk menyirip genap dengan jumlah anak daun yang genap, anak daun duduk berhadap-hadapan, berbulu halus, panjang daun $16,5 \mathrm{~cm}$, lebar $2 \mathrm{~cm}$, tangkai daunberbulu halus, ujung daun runcing, tepi daun rata dengan tekstur yang lembut dan halus.Spora Terletak di tepi daun bagianbawah daun, berbentuk bulat dengan warna coklat. Nephrolepis hirsutula berpotensi bahan panganpada daun yang masih muda (Darma, 2012).

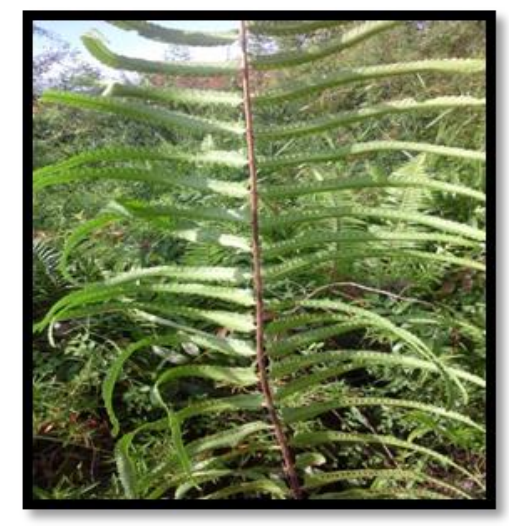

Gambar 5. Nephrolepis hirsutula 
Nephrolepis falcata (paku sepat) adalah tumbuhan teresterial yang ditemukan di samping lapangann futsal, bentuk akar serabut. Habitat tumbuhan ini di rawa gambut. Tinggi batang $50 \mathrm{~cm}$, bentuk batang tegak dan agak kecil. Warna daun hijau dengan ujung tumpul, daun majemuk menyirip genap dengan jumlah anak daun yang genap, kedudukan anak daun berselang-seling dengan panjang $10 \mathrm{~cm}$, lebar $3 \mathrm{~cm}$, tepi daun bergerigi, dan tangkai daun rapat. Pada permukaan tangkai daun terdapat bulu-bulu berwarna coklat tua. Letak sorus di permukaan bawah daun berbentuk bulat kecil-kecil berwarna. Dari segi keindahan Nephrolepis falcata cukupberpotensi sebagai tanaman hiasdan dikonsumsi sebagai bahan pangan pada daun yang masih muda (Kinho, 2009).

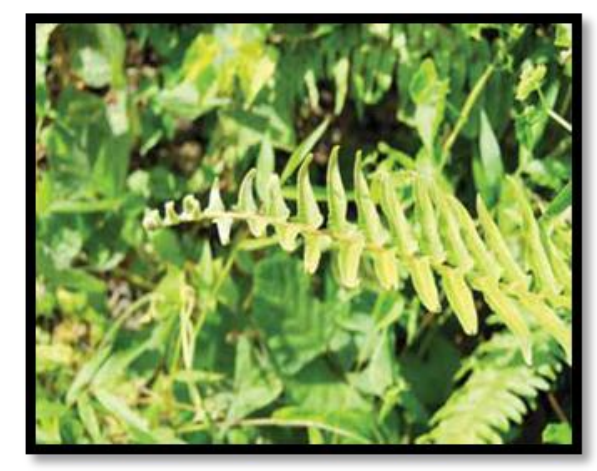

Gambar 6. Nephrolepis falcata Sumber : Kinho, 2009

Nephrolepis cordifolia (paku sepat) adalah tumbuhan teresterial, yangditemukan di samping lapangann futsal,sistem perakaran serabut berwarna coklat. Tinggi $100 \mathrm{~cm}$, batang berwana hijau, terdapat bulu-bulu halus pada sepanjang batang.Daun merupakan daun majemuk menyirip genap dengan jumlah anak daun yang genap, anak daun berhadap-hadapan,ketika daun masih muda menggulung berwarna hijau, tangkai daunnya berbulu dengan panjang $11 \mathrm{~cm}$, dan lebar $18 \mathrm{cmpermukaan}$ daun halus, tepi daun rata, dan ujung daun runcing. Sorus terdapat di peruratan daun bagian tepi dan tengah, berbentuk bulat. Nephrolepis cordifolia berpotensi sebagai Obat dan bahan pangan (Kinho 2008). Biasanya paku sepat ini digunakan untuk penyembuhan beberapa penyakit, diantaranya penyakit diabetes, infeksi yang disebabkan jamur ataupun bakteri. Karena pada tumbuhan ini memiliki antioksidan dengan nilai $\mathrm{IC}_{50} 31,72 \mu \mathrm{g} / \mathrm{mL}$. Pada daun yang muda paku sepat ini dapat dikonsumsi sebagai bahan pangan (Priyanto, 2013). 


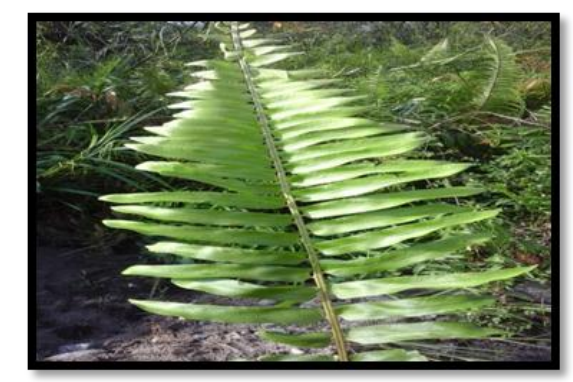

Gambar 7. Nephrolepis cordifolia

Dryopterisfilix-mas merupakantumbuhan teresterial, yangditemukan dibelakang Aula, akar berbentuk serabut. Batangnya berwarna hijau, bentuk batang bulat, permukaan batang terdapat bulu-bulu halus dengan ukuran tinggi batang mencapai $\pm 60 \mathrm{~cm}$ berwarna hijau. Daun berbentuk majemukmenyirip genap dengan jumlah anak daun yang genap dengan lebar $0,3 \mathrm{~cm}$, panjang daun $11 \mathrm{~cm}$. kedudukan anak daun berhadap-hadapan, permukaan atas daun berwarna hijau tua dan hijau muda pada permukaan bawah. Tepi daun dengan ujung daun runcing. Dryopterisfilix-mas berpotensi Sebagai tanaman hiaskarena menarik sehingga terlihat indah untuk dijadikan sebagai tanaman hias (Kinho 2008).

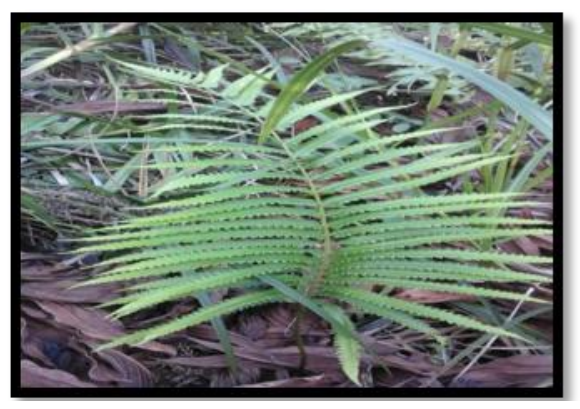

Gambar 8. Dryopterisfilix-mas

Adiantum tenerum (paku suplir) merupakantumbuhan epifit yang mempel pada tumbuhan lain, memiliki sistem perakaran serabut, tumbuhan ini ditemukan di belakang gedung peradilan syariah. Batang berwarna hujau dengan tinggi berkisar $5 \mathrm{~cm}$, daun berwarna hijau, ujungnnya bulat telur, panjang $10 \mathrm{~cm}$, lebar 0,7 , tepi daun bergerigi, ujung tumpul. Ukuran jenis tumbuhan ini sekitar $35-60 \mathrm{~cm}$, tangkai hitam mengkilat licin, bentuk helaian daun agak memanjang, dengan tepi bergerigi, daun melekuk membentuk delta yang merupakan tempat spora dalam indusia Pada paku ini tidak ditemukan adanya sorus karena pada daun yang diamati masih muda. Potensi pemanfaatan tumbuhan ini sebagai tanaman hiaskarena menarik sehingga terlihat indah untuk dijadikan sebagai tanaman hias (Jamsuri, 2007). 


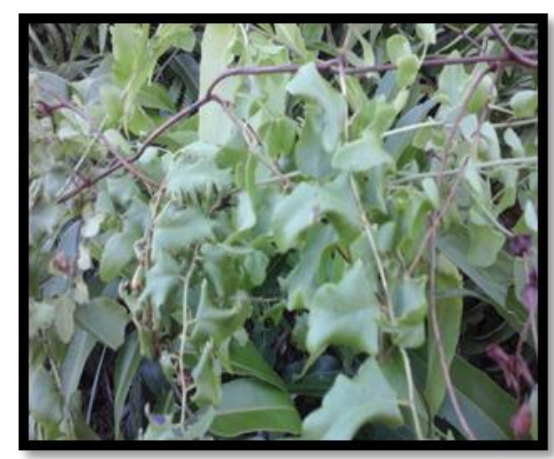

Gambar 9. Adiantum tenerum

Adiantum peruvianum (paku suplir)ditemukan disamping lapangan futsal sistem perakaran serabut. Tinggi paku ini $\pm 1 \mathrm{~m}$ batang berwarna hijau muda. Tumbuhan ini termasuk tumbuhan epifit yang menempel pada tumbuhan lain. Daun majemuk berwarna hijau daun, panjang $4 \mathrm{~cm}$, lebar $1,3 \mathrm{~cm}$, tepi daun rata dan ujung daun tumpul. Bentuk membulat. Tangkai-tangkainya berwarna hijau mengkilap. Pada paku ini tidak ditemukan adanya sorus karena pada daun yang diamati masih muda. Potensi pemanfaatan tumbuhan ini sebagai tanaman hias karena menarik sehingga terlihat indah untuk dijadikan sebagi tanaman hias (Jamsuri 2007).

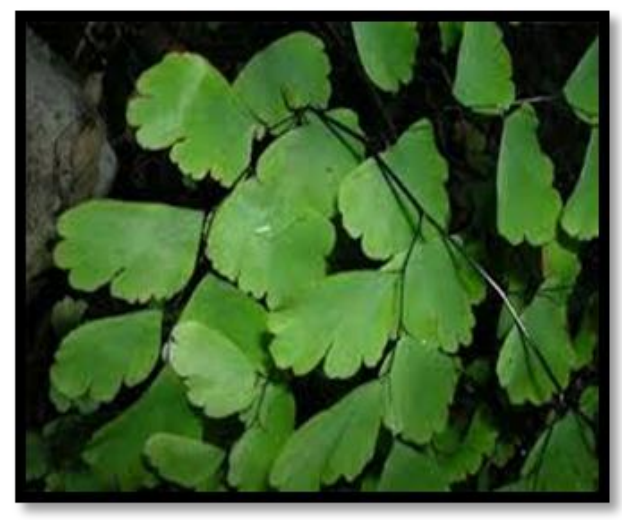

Gambar 10. Adiantum peruvianum

Athrium $S p$ (paku sayur) merupakan tumbuhan teresterial,memiliki akar serabut, yang ditemukan di belakang gedung ruang dosen. Batang Athyrium sp tegak dan berkayu, berbentuk bulat, panjang, permukaan kasar, terdapat rambut-rambut yang berwarna coklat muda agak kehitaman dan mudah lepas apabila disentuh yang melekat pada batangnya. Panjang batang 3 meter. Athyrium sp. Daun merupakan daun majemuk menyirip genap, kedudukan anak daun berhadap-hadapan. Panjang daun $4 \mathrm{~cm}$ dan lebar $2 \mathrm{~cm}$, bentuk daunnya berupa memanjang, meruncing. Ujung daun meruncing dengan tepi daun bergerigi. Sorus pada Athyrium sp terletak di bawah daun. Potensi pemanfaatan tumbuhan ini sebagai tanaman hias karena memiliki bentuk yang menarik dan indah, dan sayur- 
sayuran, pada Athrium sp ini dapat dikonsumsi sebagai sayuran ketika daunnya itu masih muda atau pucuk-pucuk daunnya (Kinho, 2012).

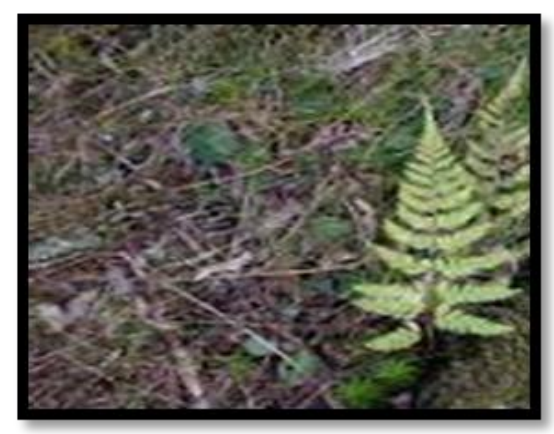

Gambar 11. Athrium Sp

Famili yang banyak ditemukan berasal dari famili Dryopteridaceae dan Polypodiaceae, sedangkan famili yang sedikit ditemukan berasal dari famili Blechnaceae, Pteridaceae, dan Woodsiaceae. Jenis Pteridophyta yang ditemukan adalah sebelas jenis dari, enam jenis Pteridophyta teresterial, dua jenis Pteridophyta epifit dan teresterial, dan tiga jenis Pteridophyta epifit. Secara singkat dapat dilihat pada Tabel 1.

Tabel 1. Jenis tumbuhan paku di kawasan kampus IAIN Palangka Raya.

\begin{tabular}{lll}
\hline \multicolumn{1}{c}{ Famili } & \multicolumn{1}{c}{ Jenis (spesies) } & \multicolumn{1}{c}{ Cara Hidup } \\
\hline Blechnaceae & Stenochlaena palustris & Teresterial dan Epifit \\
& Pteris vittata & Teresterial \\
Pteridaceae & Pteris longifolia & Teresterial \\
Polypodiaceae & Pityrogramma calomelanos & Teresterial dan Epifit \\
& Adiantum tenerum & Epifit \\
& Adiantum peruvianum & Epifit \\
& Nephrolepis hirsutula & Teresterial \\
Dryopteridaceae & Nephrolepis & Teresterial \\
& Falcata & Teresterial \\
& Nephrolepis & \\
& Cordifolia & Epifit \\
& Dryopteris filix-mas & Teresterial \\
\hline Woodsiaceae & Athrium Sp & \\
\hline
\end{tabular}

Inventarisasi tumbuhan paku di kawasan IAIN Palangka Raya dalam penelitian ini merupakan salah satu bentuk kegiatan untuk memperoleh media pembelajaran yang akan membantu pemahaman peserta didik tentang ciri morfologi dan klasifikasi tumbuhan paku. Hasil penelitian ini memberikan informasi tentang klasifikasi tumbuhan dalam bentuk fotofoto hasil penelitian. Foto-foto hasil penelitian menjadi salah satu alternatif media pembelajaran klasifikai tumbuhan.

Pengunaan media pembelajaran berupa foto-foto hasil penelitian diharapkan dapat membantu peserta didik dalam penyampaian dan pemahaman materi yang diajarkan. Hal ini sejalan dengan pendapat Nugrahani (2007) yang menyatakan bahwa kesulitan siswa 
memahami konsep dan prinsip tertentu dapat diatasi dengan bantuan media pembelajaran. Bahkan media pembelajaran berupa alat bantu diakui dapat melahirkan umpan balik yang baik dari anak didik. Dengan memanfaatkan taktik alat bantu yang mudah diterima (acceptable), guru dapat menggairahkan minat belajar siswa.

\section{SIMPULAN}

Hasil penelitian ditemukan 11 jenis tumbuhan paku yang berada di kawasan Kampus IAIN Palangka Raya, yang dikelompokkan ke dalam 5 famili. Di antara dari 5 famili itu, famili Dryopteridaceae memiliki jumlah yang banyak dari pada famili yang lainnya sebanyak 4 spesies yang ditemukan. Jenis Pteridophyta yang ditemukan adalah sebelas jenis dari, enam jenis Pteridophyta teresterial, dua jenis Pteridophyta epifit dan teresterial, dan tiga jenis Pteridophyta epifit.

\section{DAFTAR PUSTAKA}

Darma, I. D. P., \& Peneng, I., N. 2007. Inventarisasi Tumbuhan Paku di Kawasan Taman Nasional Laiwangi-Wanggameti Sumba Timur,Waingapu, NTT. Jurnal Biodiversitas. 8(3) : 242-248.

Derting, T. L., \& Ebert-May, D. 2010. Learner-centered inquiry in undergraduate biology: positive relationships with long-term student achievement. CBE-Life Sciences Education, 9(4), 462-472.

Handika, J. 2009. Pembelajaran Fisika Melalui Inkuiri Terbimbing Dengan Metode Eksperimen dan Demonstrasi Ditinjau Dari aktivitas dan Perhatian Mahasiswa. JP2F, 1(1): 9-23.

Arini, D. I. D., \& Kinho, J. (2012). Keragaman Jenis Tumbuhan Paku (Pteridophyta) di Cagar Alam Gunung Ambang Sulawesi Utara. Info BPK Manado, 2(1), 17-40.

Jamsuri. 2007. Keanekaragaman Tumbuhan Paku Disekitar Curug Cikaracak, Bogor, Jawa Barat. Proram Studi Biologi, Jurusan Pendidikan MIPA Fakulatas Sains Dan Teknologi Universitas Islam Negeri Syarif Hidayatullah Jakarta.

Kemendikbud. 2016. Permendikbud Nomor 22 Tahun 2016 Tentang Standar Proses Pendidikan Dan Menengah. Jakarta: Kemendikbud.

Kinho, J. 2009. Mengenal beberapa jenis tumbuhan paku di kawasan hutan payahe Taman Nasional Aketajawe Lolobata Maluku Utara. Manado: Balai Penelitian Kehutanan Manado.

Lubis S. R, 2009, Keanekaragaman dan Pola Distribusi Tumbuhan Paku di Hutan Wisata Alam Taman Eden Kabupaten Toba Samosir Provinsi Sumatera Utara. Tesis, Medan, Universitas Sumatera Utara.

Nugrahani, R. 2007. Media Pembelajaran Berbasis Visual Berbentuk Permainan Ular Tangga Untuk Meningkatkan Kualitas Belajar Mengajar di Sekolah Dasar. Lembaran Ilmu Kependidikan Jilid 36, No. 1. 
Nurchayati, N. 2010.Hubungan Kekerabatan Beberapa Spesies Tumbuhan Paku Familia Polypodiaceae Ditinjau Dari Karakter Morfologi Sporofit Dan Gametofit, 7(19):9-18.

Purnawati,U., Turnip,M., Lovadi, I. 2014. Eksplorasi Paku-Pakuan (Pteridophyta) Di Kawasan Cagar Alam Mandor Kabupaten Landak. Jurnal Protobiont 3(2):155 - 165.

Priyanto, A. 2013. Isolasi Senyawa Aktif Antioksidan Dari Fraksi Etil Asetat Tumbuhan Paku Nephrolepis Falcata (Cav.) C. Chr. Jakarta: Universitas Islam Negeri Syarif Hidayatullah

Rizky, M. A., Utami, B., \& Budhiretnani, D. A. 2016. Inventarisasi Tumbuhan Paku (Pteridophyta) Di Kawasan Wisata Air Terjun Dholo, Kabupaten Kediri

Steenis, C. G. G. J Van., 2013. Flora untuk Sekolah Di Indonesia. Cetakan Ketigabelas. PT. Pradnya Paramita, Jakarta.

Suryana, 2009, Keanekaragaman Jenis Tumbuhan Paku Terestrial dan Epifit di kawasan PLTP Kamojang Kab. Garut Jawabarat. Jurnal Biotika, 1(47).

Taufiq, M, Dewi N. R., Widiyatmoko A.2014. Pengembangan Media Pembelajaran IPA Terpadu Berkarakter Peduli Lingkungan Tema "konservasi" Berpendekatan ScienceEdutainment. Jurnal Pendidikan IPA Indonesia, 3 (2)140-145.

Tjitrosomo, S. Sutarmi, H. Sudarnadi \& A. Zakaria, 1983, Botani Umum 3. Bandung, Penerbit Angkasa.

Tjitrosoepomo, G, 2005, Taksonomi Tumbuhan (Schizophyta, Thallophyta, Bryophyta, Pteridophyta), Yogyakarta, Gadjah Mada University Press.

Tjitrosoepomo, G. 2009. Morfologi tumbuhan. Yogyakarta: universitas Gajah Mada. 